\title{
Community Health Nursing In Oman
}

\author{
Al-Zadjali $\mathbf{M}^{1}$, Sinawi $\mathbf{F}^{1}$, Sheeba $\mathbf{M}^{1}$, Al Busaidi $\mathbf{M}^{1}$, Al Jabri $\mathbf{S}^{1}$ and Silbermann $\mathbf{M}^{2 *}$ \\ ${ }^{1}$ The Oman Specialized Nursing Institute, Sultanate of Oman, Oman \\ ${ }^{2}$ The Middle East Cancer Consortium, Israel
}

*Corresponding author: Dr. Michael Silbermann, Executive Director, P.O. Box 7495, Haifa 31074, Israel, Tel: 972-505606335; E-mail: cancer@mecc-research.com

Rec date: Jul 29, 2014, Acc date: Sep29, 2014; Pub date: Oct 1, 2014

Copyright:@ 2014 Al-Zadjali M. This is an open-access article distributed under the terms of the Creative Commons Attribution License, which permits unrestricted use, distribution, and reproduction in any medium, provided the original author and source are credited.

\section{Introduction}

Community health nursing is one of the nursing specialties that have always been valued for its role in providing care in a variety of practice settings including homes, schools, work places or other community institutions [1]. Community health nurses (CHNs) provide care to individuals, families and communities regardless of their age, gender, health or socioeconomic status. They provide their services in order to promote health; prevent diseases and restore health [2]. Community health nursing is a population-focused practice that aims to improve the health of the people. It is grounded in the population health status taking into consideration broad determinants of health and emphasizing all levels of prevention with a preference for primary prevention [2]. As the health care systems are changing, more emphasis is placed on prevention rather than cure. Thus, the focus is moving towards community based interventions [3].

Sultanate of Oman is one of the Middle Eastern Countries that is located in the southeast coast of the Arabian Peninsula. It is about $309,500 \mathrm{KM} 2$ and has a population of around four million of which 1.7 million are foreigners and residents [4]. Most of the people in Oman are from age group of 15-64years with the life expectancy of the population is 72.3 years [5]. People of Oman are ethnically diverse and speak several different languages with Arabic being the main language spoken by most people of the country. Most of the Omanis are Muslim [6] and Islam calls for health promotion and disease prevention mainly by advocating for a healthier life style that includes activities such as encouraging moderate eating, regular exercise, no alcohol, tobacco or substance misuse, personal hygiene, breast feeding and hope and happiness based on the Holy Quran and the teaching of the Prophet Mohammed (Peace be upon Him).

\section{Primary Healthcare in Oman}

Prior to 1970, there were only 2 hospitals in Muscat region only. After 23rd July 1970, Oman has witnessed its Renaissance. A month later, a Royal Decree was issued established Ministry of Health $(\mathrm{MOH})$. Since then, was the lead government agency that provides most of the healthcare services including strategic planning, formulating health policies, supervising and monitoring all health related programs [7]. $\mathrm{MOH}$ started with building its basic infrastructure in the country by establishing a number of hospitals and health centers all overOman. $\mathrm{MOH}$ has also shown an interest in providing preventive services and this was clear in establishing health centers, public health units and units for malaria control. In addition, immunization, vector control, water purification and health education were some major activities of $\mathrm{MOH}$ since its establishment. $\mathrm{MOH}$ has taken the strategy of five-year health development plans. During the first five-year health development plan (1976-80), the old hospitals were renovated and developed. Oman, as a member state of WHO had adopted the global goal of "Health for All by Year 2000". The primary healthcare services were given the priority in Oman since the AlmaAta declaration in 1978 as it was considered as the first portal of entry to all levels of care as well as the key strategy for achieving the target of the global goal. Consequently, in year 1980, the number of the health centers increased to 55 including 5 health centers with beds $[13,14]$.

The second Five-Year Health Development Plan (1981-85) considered primary health care as the basic entry point to all levels of healthcare. This has been evident in the increased coverage. There were either well-established health units or mobile medical teams utilized to provide health services to the remote areas. Several health programs were established by then such as the Program for Control of Tuberculosis (1981), Extended Program for Immunization (1981), Program for Preventing Blindness (1982) and Program for Control of Diarrheal Diseases (1985). In order to promote PHC further, the "National Primary Health Care Committee" was established in year 1985. Several new programs were added following the recommendations of the committee. During the third five-year health development plan (1986-1990) more health centers were added to the system. Some new programs for attaining maternal and child health as well as controlling the acute respiratory diseases was established. To decentralize the system and accelerate the expansion of health services, the directorates general of health services were established in different regions in year 1990. The fourth five-year health development plan (1991-1995) focused on a number of health problems and risk groups. Around 23 health programs were focused on different target diseases. All essential element of PHC were covered especially after publishing a document called "Components of Primary Health Care in Oman 1991-1995" that served as a guide for providing primary healthcare. The services were further expanded and PHC called for integration of curative services into the system. A new system of "Wilayat Health System" was developed taking the decentralization to the wilayat level. This allowed further awareness of the healthcare providers of the needs of the community as well as the resources needed or available. This system ensured covering essential elements of PHC such as community participation and self-reliance, equity of health services, better coverage and efficient health care delivery. Following that, in the fifth five-year health development plan (1996-2000), MOH further exhibited an interest in PHC by establishing a special program "Program to strengthen Primary Health care" to identify and manage challenges that face implementing all strategies of PHC. By year then, 116 health centers were established and 34 Wilayat and local hospitals $(\mathrm{MOH}, 2012)$. The sixth five-year health development plan (2001-2005) continued expanding the services and establishing new program. The seventh five-year health development plan (2006-2010) further expanded the development of health services infrastructure, disease prevention, primary care and community involvement as well as health promotion as a result of new socio-demographic and social changes that were witnessed by the country (Alshishtawy, 2010). $\mathrm{MOH}$ 
Page 2 of 4

is currently implementing the eighth five-year health development plan (2011-2015) that is continuing to development the services provided to the public in Oman. The Table 1 below shows the infrastructure and human resources by 2008 .

\section{The Evolvement of Community Health Nursing Services}

Primary care is a major component of community based services where nurses work in partnership with their communities in collaboration with other healthcare professionals. The principles of primary health are participation (by the community), partnership (between the community and health professionals), protection from and prevention of illness and disease, and the promotion of health education $(\mathrm{MOH}, 2012)$. With the continued advancement of primary healthcare in Oman and the decentralization of the healthcare services, the number of the health centers was increased in order to provide services to people in their own areas. However, with the growing population and increased burden of diseases as well as longevity, the demand for qualified workforce increased. In addition, as most of the nurses in Oman were from different countries such as India and Philippines...etc., the Ministry considered training Omani nurses as the main pillars for achieving self-sufficiency in healthcare human resources (MOH, 2012). Thus, the Ministry paid special attention and inaugurated different nursing institutes in different parts of the Sultanate (MOH, 2012). Community Health Nursing was taught as a course in the basic nursing curriculum that included theory as well as clinical hours. The students were attached to different primary health centers, industries, center for physically challenged children etc. A similar practice was also taking place in Sultan Qaboos University and University of Nizwa. However, these courses were covering just the basic concepts in Community Health Nursing that was not enough to prepare specialized Community Health Nurses. Consequently, the past decade has witnessed a great improvement in the community health services and showed that there is a need to nationalize provision of the service to all citizens in all regions (MOH 2014).

\section{The Need for Community Health Nursing Services}

In recent years, Oman has witnessed rapid growth in population density and an increase in longevity and life expectancy as a result of changes in the socioeconomic status of the people and improvement of health status due to the improvement of health services (WHO, 2012). In the upcoming years, it is predicted that more citizens will reach old age, changing the current population pyramid. In addition, due to the changes in life style, more people are suffering from life-style related chronic diseases. According to WHO's Non-communicable Diseases Country Profiles (2011), 83\% of deaths in Oman are caused by noncommunicable diseases. These diseases included Cardio-vascular diseases, Cancers, Diabetes, Respiratory diseases and other diseases. With this trend, Oman is facing another life-threatening challenge of road traffic accidents that accounts for $11 \%$ of all deaths in the country in addition to causing disabilities raising the healthcare costs [11-13]. Furthermore, the population is becoming aware of their needs and their expectations are on the rise [14]. With modernization, new global and societal challenges are emerging. This situation is demanding for community health services in the Sultanate $(\mathrm{MOH}, 2012)$. This was further emphasized by short term consultancies [15-17] that proposed a need to focus on community health services especially in rural areas by moving care closer and deeper into the community. Community health nursing services through the implementation of health promotion and health education activities could best serve to address some of these issues $[17,18]$. Thus, $\mathrm{MOH}$ has paid a great attention to address all these demands by developing community health services in the country.

\section{Preparing Community Health Nurses}

\begin{tabular}{|c|c|c|c|c|c|c|}
\hline Provider & Hospitals & Hospital beds & $\begin{array}{l}\text { Health Centers \& } \\
\text { Extended Health Centers }\end{array}$ & Clinics & Physicians & Nurses \\
\hline Ministry of Health & 49 & 4,605 & 167 & 0 & 3,620 & 9,277 \\
\hline $\begin{array}{l}\text { Sultan Qaboos University } \\
\text { Hospital }\end{array}$ & 1 & $410^{*}$ & 1 & 0 & 329 & $833^{*}$ \\
\hline Royal Omani Police & 1 & 50 & 0 & 3 & 34 & 101 \\
\hline $\begin{array}{l}\text { Medical Services of Diwan of } \\
\text { Royal Court }\end{array}$ & 0 & 0 & 0 & 1 & 18 & 46 \\
\hline Ministry of Defense ${ }^{\star *}$ & 3 & 260 & 0 & 31 & - & - \\
\hline $\begin{array}{l}\text { Petroleum Development of } \\
\text { Oman }\end{array}$ & 0 & 0 & 0 & 9 & 11 & 36 \\
\hline Private Sector & 4 & 148 & 0 & 766 & 1,182 & 941 \\
\hline Total & 58 & 5,473 & 168 & 810 & 5,194 & 11,233 \\
\hline
\end{tabular}

*Data updated from: Ministry of National Economy, Statistical Year Book 2009, Issue 37, $2009{ }^{* *}$ Complete information currently unavailable. Note: There are in addition 364 private pharmacies. Source: Alshishtawy M (2010) Four Decades of Progress; Evolution of the health system in Oman. Sultan Qaboos University Medical Journal, 10: Pp 12-22 [10]

Table 1: Health infrastructure and human resources in Oman (2008)

The role of a community health nurse focuses on the community as a client. This requires advanced knowledge, skills and competencies that enable these nurses to practice different roles that has been assigned to them such as an advocate, a health educator and a 
community organizer [19]. For the same purpose, in the year 2004, the Department of Nursing and Midwifery (DNMA) at the MOH employed a senior nurse specialized in Community to do a need analysis and develop a training program to strengthen community health nursing practice. As a result, a 16-week on Job Training program for community health nurses was initiated in Muscat Governorate in Wilayat Al Amerat as a pilot study. Six months later, the program was approved and extended to threeother Governorates namely North Sharqiya, North Batinah and Al-Dhakliya. At that time, it was suggested that Oman is in a positive position to integrate community health nursing into the existing primary health care structure and to align these services with secondary and tertiary care to further progress the continuity of care for the country's population [16]. Based on these expert recommendations, community health nursing services were linked to primary health care by basing the services in the existing primary health care centers. This enabled the development of a flexible and interchangeable workforce within an already established structure. This model of service further strengthened the existing system and avoided the concept of developing an independent service with no infrastructure and no supporting mechanisms.

In year 2007, a cost analysis exercise was carried out. It demonstrated that community health care services are both cost effective and viable when compared to the costs incurred for tertiary and secondary levels of service [20]. For instance, one patient's day in a tertiary level hospital cost was around Omani Riyal (OR) 50-75 (USD 130-180) compared to OR 3.620 (USD 9.5) for one patient visit in the community by a community health nurse. This exercise demonstrated a profound saving in terms of costs incurred [20]. In addition, technical consultation was requested from the International Council of Nursing (ICN) and WHO in year 2009. The consultants helped to develop the conceptual framework for Community Health Nursing in education, regulation and practice and sensitizing decision makers at $\mathrm{MOH}$ on experiences of other countries. Dialogue continued with all stakeholders and decision makers in and outside the $\mathrm{MOH}$ on the need of developing Community health nursing as a post basic program.

In 2012, the Ministry of Health signed a Memorandum of Understanding with Cardiff University for a partnership in developing and delivering a BSc (Hons) Community Health Nursing Practice Program [21]. In 2013, the first group of 20 nurses graduated successfully from the same program and 24 were admitted into the second cohort. A year later, all the governorates in Oman started calling for Community Health Nursing service. However; it is worth to mention that the service is only actively implemented in two out of eleven health regions i.e. Muscat and North Batinah Region with 224 staff nurses. The other nine regions started recently to work on the awareness about the service as the first step to initiating the program.

\section{Current Practice of Community Health Nurses}

Currently, community health nurses receive patients either as a referral from the health centers or from hospitals or community [22]. The referred patients are assessed in the initiation phase. Those who are found to have complications and do not meet the criteria for admission, are referred back to the physicians for further interventions. However, those who are found to be meeting the admission criteria, are admitted into the service and individualized patient and family centered care that is culturally oriented are delivered to him/ her in their home. Community health nurses receive different types of cases including but not limited to hypertension, diabetes, cerebrovascular accidents, cancer, mental disorders, neurological disorders...etc. The care is continued to be delivered at no cost. The care is only terminated when either the patient becomes fit to be discharged or upon patient or family's request.

Home visiting is just one aspect of the role of community health nurses. Community health nurses function as clinicians, as advocates, collaborators, consultants, counselors, educators, researchers and case managers in different settings of the community including schools, community centers and work places. Therefore, in order to regulate and control the role of the community health nurses, it was necessary to establish the bylaws and policies that describes and dictates the role of a community health nurses. Consequently, a national group was formed in year 2011 by the former Oman Nursing and Midwifery Council (ONMC). After ONMC, the task has been transferred to a national core group for primary health care and community services that was re-formed in year 2013 with 15 members from different regions of the country with different backgrounds including community nurses, discharge planners, administrators and educators as well as researchers. This group revised the scope and standards of practice, policies and procedures, job descriptions for both community health nurse and discharge planners and sent it for expert opinion prior to sending it for final approval.

Recently, in addition to home care and caring for patients with disability, three more healthcare programs were integrated into the community health services in Oman. These programs included: the elderly care program, palliative care and heart failure services. The National Program for the Elderly Care was initiated to provide comprehensive assessment and screening of older persons in the community through a pre-designed clinical protocol. It promotes optimal health for the elderly by maximizing independence, identifying strengths of the older people and working in collaboration with the client to enhance or maintain these strengths. In February 2011, Oman Cancer Association, a non-governmental agency, established Palliative care in Oman in collaboration with MOH. Two training workshops were conducted (Basic and Advanced). Nurses were sent back to their institutions with action plans, to formulate Palliative care working teams within their institutions. The Heart failure services program has been integrated within community services in North Batinah Governorate as a pilot study in October, 2013 after meeting with all stakeholders, community nurses, and all other health care providers and training them for working in this project. In April, 2014 the program was evaluated and was found to be successful [23].

\section{Challenges and Recommendations}

Although $\mathrm{MOH}$ has exerted a great effort in developing and advancing community health nursing program, this specialty did face and still facing several challenges. In Oman, as it is the case in many other countries, community health nursing was not regarded as important as hospital-based nursing previously. It has not received much attention in terms of policy, research, workforce development. However, once the need for the service was recognized, $\mathrm{MOH}$ has put a great attention into developing this specialty and advancing it. As $\mathrm{CHN}$ is a fairly new specialty, the available resources for the provision of community health care services are very limited. These resources are identified in terms of equipment, transportation, staffing, and budget for program implementation. As a result, a professionally organized support from mainstream nursing to ensure that 
community health nursing is positioned as a united force in efforts to advance the health of community is needed. Although the first steps of this have been initiated, it is worth to mention that program fragmentation to different specialties must be stopped. This will not only increase the cost on the healthcare system but will lead to lower quality of care delivered as the concept of providing holistic, comprehensive family centered care are not going to be met. In addition, as $\mathrm{MOH}$ aims towards achieving equity of care delivery to all citizen and the community health service is currently in its transition phase to establish it as a national service $(\mathrm{MOH}, 2014)$, it is important that the service status in terms of resources, education, qualification, service and practice should be analysed, discussed and improvement plans should be established. Although community health nursing services are delivered under the umbrella of PrimaryHealth Care, it is recommended to study the feasibility of having independent centres ofexcellence for community health, under the supervision of $\mathrm{MOH}$, that are well equipped with state-of-art equipment and a multidisciplinary team ready to provide services to people in the community based on best available evidence and conduct studies that serve both the community and healthcare system nationally and internationally $[24,25]$.

Although community health nursing is in its initial phase in many governorates of Oman, with the valuable support of $\mathrm{MOH}$ and the dedication of community health nurses, much has been achieved with in few years that its success stories are never ending.

\section{References}

1. Phyllis M (2009) Community Health Nursing. American Journal of Nursing109: 19.

2. Stanhope M and Lancaster J (2010) Foundations of Nursing in the Community: Community Oriented Practice. St. Louis: Mosby.

3. Marvasti F and Stafford R (2012) From Sick Care to Health CareReengineering Prevention into the U.S. System. The New England Journal of Medicine 367: Pp889-891.

4. National Center for Statistics and Information (NCSI) (2014) Population in a week.

5. World Health Organization (2010) Health Profile: Oman.

6. Ministry of Tourism (2014) Oman.

7. Ministry of Health (2012) Primary Health Care in Sultanate of Oman.
8. Ministry of Health (2012) Directorate General of Education \& Training (DGET).

9. Ministry of Health (2012) Main Function of the Ministry of Health.

10. Alshishtawy M (2010) Four Decades of Progress; Evolution of the health system in Oman. Sultan Qaboos University Medical Journal 10: Pp 1222.

11. World Health Organization (2010) Health Profile: Oman.

12. World Health Organization (2011) Non communicable diseases country profiles 2011-WHO global report.

13. World Health Organization (2012) Health Status and demographic.

14. Al-Lamki L (2010) Life loss and disabilities from traffic accidents. Sultan Qaboos University Medical Journal, 10: 1-5.

15. Rahim I (2004) Review of Primary Health Care in Oman and Strategic Directives for the Future, World Health Organization - Short Term Consultancy.

16. Schober M (2007) Development of Advanced Community Nursing/ Nurse Practitioner Roles and Educational Programs in Oman, World Health Organization-Short Term Consultancy.

17. Ghebreiwet $\mathrm{T}$ (2005) Situation analysis of the Advanced Nursing Practice Role with reference to Primary health Care in Oman, World Health Organization -Short Term Consultancy.

18. Department of Health (2006) Modernizing nursing careers; Setting the direction.

19. Kulbok P, Thatcher E, Park E and Meszaros P (2012) Evolving public health nursing roles: Focus on community participatory health promotion and prevention. OJIN: The Online Journal of Issues in Nursing: 17 .

20. Sheeba M and Patmore L (2004) Needs Assessment for Community Health Nursing Program in Oman. Directorate of Nursing \& Midwifery Affairs.

21. Cardiff University (2012) Oman collaboration.

22. Al-Busaidi M. (2013) Community Health Care Services in Oman. Oral presentation, the international Palliative Care Conference, Muscat, Oman.

23. Al-Buloshi M. (2014). Pilot Study of Heart Failure in North Batinah. Oralpresentation, Non-Communicable Diseases Initiatives Workshop, Muscat, Oman.

24. Ministry of Health, Directorate of Nursing and Midwifery Affairs (2014) Evaluation of existing community health nursing services in Oman.

25. Ministry of Health (2012) Development of Health Services and Health Care. 